\title{
The Role of the Microbiome in Cancer Initiation and Progression: How Microbes and Cancer Cells Utilize Excess Energy and Promote One Another's Growth
}

\author{
Corrie M. Whisner ${ }^{1}$. C. Athena Aktipis ${ }^{2}$
}

Published online: 13 February 2019

(C) The Author(s) 2019

\begin{abstract}
Purpose of Review We use an ecological lens to understand how microbes and cancer cells coevolve inside the ecosystems of our bodies. We describe how microbe-cancer cell interactions contribute to cancer progression, including cooperation between microbes and cancer cells. We discuss the role of the immune system in preventing this apparent 'collusion' and describe how microbe-cancer cell interactions lead to opportunities and challenges in treating cancer.

Recent Findings Microbiota influence many aspects of our health including our cancer risk. Since both microbes and cancer cells rely on incoming resources for their survival and replication, excess energy and nutrient input from the host can play a role in cancer initiation and progression.

Summary Certain microbes enhance cancer cell fitness by promoting proliferation and protecting cancer cells from the immune system. How diet influences these interactions remains largely unknown but recent evidence suggests a role for nutrients across the cancer continuum.
\end{abstract}

Keywords Cancer $\cdot$ Neoplasms $\cdot$ Neoplastic processes $\cdot$ Metastasis $\cdot$ Cell proliferation $\cdot$ Microbiome $\cdot$ Microbiota $\cdot$ Microbe $\cdot$ Diet $\cdot$ Nutrition $\cdot$ Western diet $\cdot$ Caloric restriction $\cdot$ Immune system $\cdot$ Inflammation $\cdot$ Ecology

\section{Introduction}

Microbes play an important role in human health and disease, including influencing our cancer risk. Microbes and cancer cells coevolve inside the ecosystems of our bodies, and both rely on incoming resources for their survival and replication. This means that what we eat - in particular, whether we have excess energy and nutrients - can affect the growth of both cancer cells and microbial cells. In addition, cancer cells and microbes can influence each other's replication and survival through the production of factors. Taken together, these facts suggest that the

This article is part of the Topical Collection on Cancer

C. Athena Aktipis

aktipis@asu.edu

1 College of Health Solutions, Arizona State University, Phoenix, AZ, USA

2 Department of Psychology, Center for Social Dynamics and Complexity, Center for Evolution and Medicine, Biodesign Institute, Arizona State University, PO Box 871104, Tempe, AZ 85287-1104, USA interactions between cancer cells and microbial cells may be very important in cancer initiation and progression.

The burden of cancer is undeniably high $-1,735,350$ newly diagnosed cases and 609,640 deaths were estimated for 2018 in the USA alone, and more than $38 \%$ of people develop cancer during their lifetime [1]. With the increasing prevalence of cancer comes an increased economic burden with direct medical costs reaching $\$ 80.2$ billion in 2015 [2]. These costs will continue to rise as 23.6 million new cases of cancer are expected by 2030 [2].

Recently, the gut microbiome has emerged as an important mediating factor of health and disease [3]. We have approximately as many microbes in and on us as we have human cells $\left(3.8 \times 10^{13}\right.$ microbial cells relative to $3.0 \times 10^{13}$ human cells [4]). The human gut houses the most diverse and metabolically varied proportion of these microbes when compared to any other body surface, serving as home to more than 1000 unique species. These species express 3.3 million genes - orders of magnitude more than the 23,000 expressed human genes [5]. Interactions between microbes and human cells play important roles in human metabolism including digestion of complex carbohydrates, production of essential amino acids, 
creation of beneficial fatty acids and vitamin compounds, and degradation of xenobiotics including environmental toxins and medications [6]. During cancer progression, these metabolic interactions between microbes and human cells may shift from ones that support health to ones that threaten it, as microbes begin interacting with cancer cells rather than healthy human cells. Indeed, microbial dysbiosis has been found to contribute to gastrointestinal cancer development [7].

It is clear that microbes play important roles in obesity, gastrointestinal, and cardiometabolic disease prevention and treatment [8], suggesting that microbes alter human metabolism. However, there are still many open questions about how microbes and cancer cells interact metabolically and how these processes contribute to cancer. In this review, we evaluate the current literature on microbiota in cancer risk, discuss how gene-environment interactions contribute to microbial mechanisms of cancer, explore how diet influences cancer risk via the microbiome, and describe how cooperative interactions between microbes and cancer cells may influence cancer.

\section{Microbes Contribute to Cancer Risk}

The human gut is a diverse ecosystem including fungi, bacteria, viruses, and archaea, of which bacteria from the phyla Firmicutes, Bacteroidetes, Proteobacteria, and Actinobacteria are most prevalent [9]. Microbes can help maintain the intestinal barrier which keeps potentially harmful organisms from reaching the epithelium where they can cause illness and injury [10]. Currently, microbes are believed to contribute to cancer risk by modifying DNA in human somatic cells thereby altering cell cycle controls, accelerating cell proliferation, and disrupting normal programs for controlled cell death that protect the body from aberrant cells.

Microbes have been linked to approximately $10-20 \%$ of human cancers [11]. To date, ten microorganisms have been designated as carcinogens by the International Agency for Cancer Research, one of which is Helicobacter pylori for its association with stomach cancer [11]. Despite observed links to cancer, these microbes reside in a large proportion of the human population, many of whom never develop cancers associated with these otherwise commensal microorganisms.

\section{Microbes and Cancer Cells Evolve in the Ecology of the Body and in the Tumor Microenvironment}

Our bodies are essentially ecosystems in which cells can evolve. As in any ecosystem, the players that best survive and replicate end up making up a larger proportion of the next generation in the population - this is the process of evolution via natural selection. Cancer is fundamentally a problem of cells evolving in the body to proliferate quickly, monopolize resources and evade cellular controls that otherwise make the body function normally [12]. Similarly, diseases caused by harmful microbes are the result of microbes overproliferating, monopolizing metabolic resources, and producing virulence factors that interfere with normal organismal functioning [13], thereby allowing further microbial imbalances (dysbiosis) to occur.

Cancer cells not only evolve inside the ecosystem of the body, they also can create a microenvironment around the tumor that facilitates their growth $[14,15]$. This tumorpromoting microenvironment has growth factors, angiogenic signals (signal growth of blood vessels that feed tumors) and fibroblast 'support' cells [14]. The microenvironment can promote the tumor, but earlier in progression, it can also be an important part of limiting the tumor. If tissue homeostasis is functioning properly and the immune system has not yet become dysregulated, then the microenvironment may help to suppress cancer [16-18].

More generally, the immune system is an important aspect of the ecology around tumors. Normally, the immune system monitors the tissues of the body for pathogens and cancer cells, targeting harmful cells for destruction. This process of immune predation helps keep potentially harmful cells from damaging healthy human tissues. However, cancer cells and pathogens can also evolve to evade the immune system just like prey evolves to evade predators [19]. Additionally, other aspects of the immune response (e.g., inflammation accompanying wound healing) can be co-opted by cancer cells and pathogens to generate a proinflammatory environment in which both cancer and pathogen cells can thrive $[14,17]$.

Tumor microenvironments can include microbes that reside in or near the tumor. Microbes can alter the microenvironment by producing factors that influence cancer cells. For example, certain strains of $E$. coli produce colibactin toxin that is more commonly found in the mucosa of individuals with colorectal cancer than healthy controls [20]. Colibactin induces cells in the microenvironment to produce growth factors which may promote tumor growth [21]. Another way that microbes can influence the microenvironment is through producing bacterial biofilms which have been associated with higher cell proliferation rates and increased risk of colorectal cancer [22]. The tumor microenvironment in gastrointestinal tissue can be influenced by all of the microbes and nutrients that are present. Therefore, what and how much we eat can have downstream impacts on the ecology of gastrointestinal tissues in ways that promote or limit cancer.

\section{Excess Energy Can Feed Both Cancer Cells and Harmful Microbes}

Microbial community structure (diversity and abundance of specific taxa) and function is rapidly influenced by acute [23] 
and long-term dietary changes [24-26], thereby highlighting the importance of dietary inputs for gut microbial community growth and maintenance. Consumption of high-fat or Western style diets has been associated with cancer [27, 28]. Further, obesity as a result of excess caloric consumption has been linked with increased cancer risk [29]. This link between excess energy consumption and cancer may be mediated by gut microbial metabolism. Microbiome transfers from obese murine donors to germ-free counterparts has been shown to lead to weight gain and fat deposition in recipient mice $[30,31]$ even when mice have the same dietary inputs $[30,32]$.

The links between cancer and obesity are clear [33], and some work suggests that microbes may play an important role in this link. Caloric restriction studies suggest that cancer outcomes are improved via increased gut microbial diversity and subsequent reductions in inflammation [34•,35•,36, 37]. This may be mediated by improved gut barrier integrity which minimizes translocation of microbial-derived inflammatory markers including lipopolysaccharide and also beneficial shifts in microbial abundance (e.g., increased abundance of Lachnospiraceae), as observed in obese women on very low calorie diets $\left(\sim 800 \mathrm{kcal} /\right.$ day) [ $\left.34^{\circ}\right]$.

As with any ecological system, the introduction of excess resources can disrupt the normal interactions among the constituents in that ecosystem. In the case of the human body, introducing excess energy can disrupt the interaction between the microbes and human somatic cells. Under ideal conditions, growth and proliferation of microbes and our somatic cells is limited by access to resources like carbohydrates, protein and fat, as well as through somatic cell cycle controls. Glucose is a preferred fuel source for most human cells, from which cellular energy in the form of ATP is used to fuel cellular processes. In the case of cancer, this otherwise oxygen-requiring pathway switches to less efficient processes such as fermentation. This metabolic disruption, referred to as Warburg metabolism [38], results in the production of lactate which destroys the extracellular environment and facilitates invasion into new tissues and metastasis. Future work should investigate whether these metabolic shifts also encourage translocation and growth of lactateutilizing microbes from the intestinal tract [39] to tumor regions. Interestingly, there is some evidence that microbes that thrive in anaerobic conditions may actually suppress replication of cancer cells, though the mechanisms of action remain unknown [40].

\section{Dietary Modification Can Influence Microbial and Cancer Cell Growth}

The introduction of agrarian (farmers and pastorals) lifestyles 10,000 years ago followed by the industrial revolution led to the emergence of a genotype more adept at processing complex carbohydrates from plant-based foods, rather than the high-protein diets of hunter-gatherers [41]. Our ancestors relied on their gut microbes to break down plant fiber so that their bodies could obtain adequate amounts of energy and nutrients. Gut microbiota express enzymes that carry out diverse reactions, including fermentation, hydrolysis, denitrification, sulfate reduction, and aromatic fission, to process compounds that persist in the gastrointestinal tract and are not metabolized by human enzymes. Today, we have access to plentiful simple and complex carbohydrates, in addition to various other foods that our bodies process with little assistance from microbes. This evolutionary mismatchespecially with regard to increased sugar consumptionappears to contribute to cancer risk [42].

\section{Fruits, Grains, and Vegetables}

Various sugars, starches, dietary fibers, and polyphenolic compounds are present in fruits, grains, and vegetables. Regular consumption of these plant-based foods has been associated with cancer prevention [43] (Fig. 1). Many of the plant components associated with improved health have been attributed to the gut microbiota and their ability to metabolize otherwise non-digestible plant stuffs into bioactive compounds including short-chain fatty acids and bioactive phytochemicals.

Short-chain fatty acids (acetate, propionate, butyrate) are byproducts of the fermentation and hydrolysis of complex carbohydrates and dietary fiber that reach the colonic microbiota [44]. Short-chain fatty acid (SCFA) effects begin at the intestine level, where butyrate is utilized as a primary fuel source for enterocytes, and extend to systemic influences where butyrate and propionate regulate glucose and lipid metabolism in the liver [45]. Butyrate also induces cell differentiation, apoptosis, and histone hyperacetylation [46, 47]. While these effects are believed to limit cancer initiation and progression, the effects of butyrate seem to depend on host genotype and SCFA concentrations. In a mouse model of colorectal cancer, in which cancer cells preferentially utilized glucose, butyrate was forced to accumulate in the nucleus where it ultimately increased histone acetylation and subsequent apoptosis thereby decreasing cancer cell proliferation [48]. Conversely, in mice with mutations in the Msh2 gene, involved in mismatch repair, microbiota-derived butyrate enhanced tumor cell proliferation [49]. Excess production of acetate in the gut has been linked to altered insulin regulation and obesity [50], and excess energy production via microbial conversion of fiber to SCFA may contribute to obesity and cancer, for which dietary intake is an important mediator $[45,51]$.

Consumption of plant polyphenols, flavonoids $[52,53]$ and glucosinolates [54, 55], is associated with reduced cancer risk. Specific microbes can convert glucosinolates from cruciferous vegetables into isothiocyanates which have anticancer 


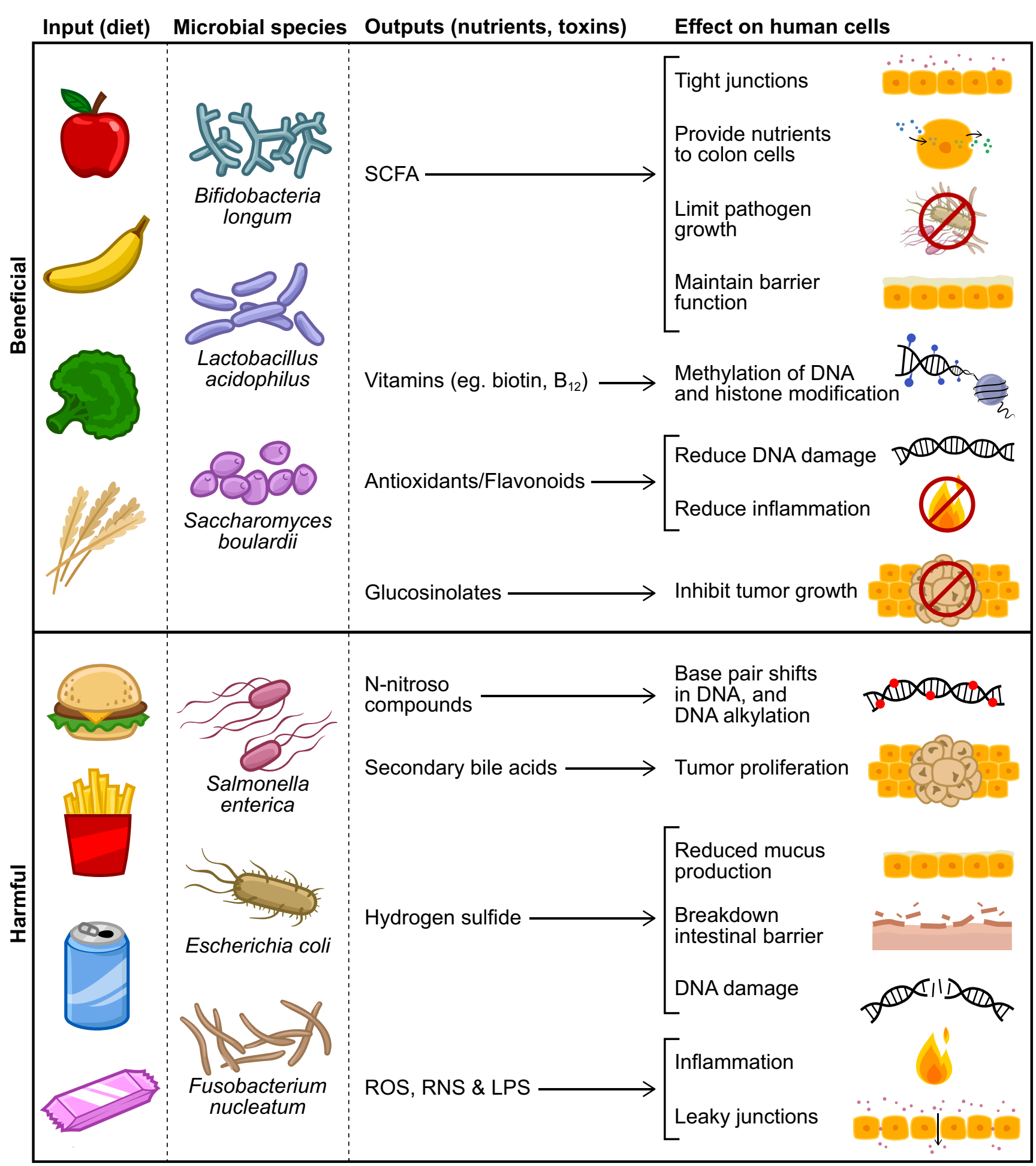

Fig. 1 Important metabolites and associated mechanisms that promote and inhibit the collusion of gut microbes and cancer cells. LPS, lipopolysaccharide; ROS, reactive oxygen species; RNS, reactive nitrogen species; SCFA, short-chain fatty acids

properties. These microbes include Eggerthella spp., Alistipes putredinis, Eubacterium hallii, and Phascolarctobacterium faecium [56], of which Eggerthella and Alistipes also degrade starch and dietary fibers [57]. Fiber-poor diets, which often lack polyphenols, enhance microbial pathogenicity and degrade barrier function via loss of intestinal mucus in animal models [58•], but how this relates to cancer risk remains understudied. A recent meta-analysis suggests that flavonoids, quercetin and apigenin, may reduce the odds of colon cancer [53]. Soy isoflavones have also been implicated in both 
anticancer and tumor-promoting pathways [59] which may be dependent on which downstream metabolites and nutrients are available to gut microbiota [60].

\section{Protein- and Fat-Containing Foods}

Proteins and amino acids can also be metabolized into phenols, indoles, ammonia, amines, sulfur compounds, and other organic acids [61]. These products are the result of hydrolysis, deamination, decarboxylation, fermentation and elimination reactions. Fatty acids and other lipids can also be metabolized by gut microbes, largely in the conversion of primary to secondary bile acids. These conversions alter both the gut microbiome as well as liver signaling [62], and have also been identified as carcinogenic compounds [63, 64].

High-protein and high-fat diets have been shown to increase the production of potentially carcinogenic branched chain fatty acids, secondary bile acids, and N-nitroso compounds $[65,66]$ (Fig. 1). Animal product-rich diets that enhance secondary bile acid production promote the presence of bile-tolerant microbes, while decreasing the abundance of plant polysaccharide-metabolizing microbes [23]. The lower the carbohydrate content paired with high-protein diets, the lower the butyrate production and beneficial Roseburia/ Eubacterium rectale abundance in feces [65]. Reductions in animal product consumption have also been associated with a lower risk of colon cancer than increasing consumption of fiber [67]. Together, these facts suggest that consuming adequate carbohydrates while avoiding excess protein may be a key to reducing cancer risk.

\section{Microbes Can Promote Cancer Through Various Mechanisms}

Ideally, normal human cells and commensal microbes cooperate to keep us healthy: we provide resources for microbes, microbes metabolize nutrients for us; we provide them with an environment to live in, they help protect us from invading pathogens [13]. In cancer, this cooperation between normal cells and beneficial microbes may break down, resulting in dysbiosis. In some cases, the cooperation between normal cells and beneficial microbes may be replaced by cooperation between cancer cells and harmful microbes.

Both microbes and cancer cells evolve in the body's ecosystem. Thus, microbes and cancer cells that interact with one another in ways that increase their proliferation and enhance their ability to avoid detection by the immune system can potentially gain an evolutionary advantage over those that do not interact in mutually beneficial ways. In other words, selection in the body may sometimes favor microbes and cancer cells that cooperate in order to gain an evolutionary advantage over non-cooperators, with cooperation being stabilized by the evolutionary mechanisms of positive assortment [68] and/or partner choice $[69,70]$. In this section, we describe several mechanisms by which microbes and cancer cells can potentially enhance one another's evolutionary fitness, including altering one another's rates of proliferation and survival. We also discuss how microbes and cancer cells could come to have high fitness interdependence [71] if they create and thrive within similar microenvironments.

\section{Microbes Can Damage Cell DNA, Initiating Cancer}

Microbes can produce genotoxins which damage DNA. For example, colibactin produced by $E$. coli and Enterobacteriaceae induces double-strand breaks in host cell DNA [72]. Microbes also produce free radicals that damage DNA [73]. B. fragilis produces reactive oxygen species that can damage host DNA and contribute to colon cancer [74].

\section{Microbes Can Increase Cancer Cell Proliferation}

Helicobacter pylori has been well studied as a bacterial strain with links to cancer. Initially, H. pylori was found to increase cell proliferation and induce tumors in Mongolian Gerbils [75]. Twelve human case-control studies further support this microbe-cancer link with data suggesting that $H$. pylori detection was a strong risk factor (odds ratio of 3.0) for gastric adenocarcinoma [76]. Interestingly, $H$. pylori colonizes stomachs of approximately $50 \%$ of the world's population but only a minority of these individuals develop gastric cancer [77]. This may depend on carcinogenic phenotypes of the host which allow $H$. pylori to persist and induce cancer proliferation in the stomach [78••] through virulence factor CagA which stimulates cell proliferation [79].

\section{Cancer Cells and Microbes Can Provide Growth Factors for Each Other}

Senescent cells (cells no longer dividing) can secrete growth factors into the nearby cellular environment to further growth of surrounding epithelial tissues. Bacteria capable of producing the toxin colibactin may mediate this signaling pathway. Specifically, E. coli production of colibactin is thought to induce the release of growth factors that promote tumor growth $[21,80]$.

\section{Cancer Cells and Microbes May Protect One Another from the Immune System}

Commensal microbes in the gut are involved in complex interactions with the human immune system. Chronic inflammation as a result of bacterial infections with H. pylori, Campylobacter jejuni, and Chlamydia psittaci 
can result in lymphomas that are mediated by overactive adaptive and innate immune signaling [81-83]. Enterotoxigenic $B$. fragilis has been linked to colon cancer in mice via inflammatory pathways that involve Stat3 signaling and increases in IL-17-secreting $\mathrm{CD}^{+}{ }^{+} \mathrm{T}$ cells [84]. Microbes also interfere with the ability of the immune system to detect them through a variety of different mechanisms, including interfering with natural killer cell activity [85], which could have an impact on the ability of the body to detect and respond to cancer cells.

\section{Microbes Can Increase Cancer Risk by Altering the Intestinal Barrier and Associated Biofilms}

The mucosal lining provides protection to the host from invading pathogens and also provides an environment to beneficial microbes that helps to cultivate them. When the mucosal lining is broken down, as happens with infection by harmful microbes, this can contribute to a pro-cancer environment with greater inflammation [86].

Some bacteria excrete polymers that can form the basis for biofilms. These biofilms create microenvironments for microbes that provide benefits including protection from external threats and access to resources/nutrients [87]. Biofilms are sometimes found in the colon, and they are often associated with colorectal cancer, particularly on the right side of the colon [22], which is the first portion of the colon that early-stage feces travel through. Tissues with biofilms on them have been associated with greater permeability of the intestinal barrier and greater immune activation [22].

\section{Microbes Can Induce Host Cell Proliferation Which Can Expand Microbes' Ecological Niche}

Many microbes can use host cells to expand their ecological niches through inducing proliferation of the cells upon which they rely. For example, viruses replicate themselves after entering the nucleus, integrating with host cell DNA and inducing cell proliferation. This is the mechanism underlying virally initiated cancers such as HPV [88]. Bacteria can also expand their ecological niches through inducing cell proliferation. Fusobacteria does this by entering the cell and inducing proliferation [89], which expands the ecological niche for the microbes [85]. This also has the effect of promoting colorectal cancer. Microbes that bind to epithelial surfaces then increase the proliferation rates of the cells they are attached to like $H$. pylori does to gastric cells [85]. In these situations, harmful microbes and cancer cells may have aligned fitness interests. Such fitness interdependence can arise anytime entities can benefit from one another's success [71], as is the case when microbes benefit from the expansion of the cancer cell population because this increases the ecological niche for microbes.

\section{Microbes Can Prompt Cells to Shift to a More Metastatic Phenotype}

One of the key steps in the transition from a benign neoplasm to a malignant cancer is the epithelial to mesenchymal transition (EMT), where cells transform from mostly stationary epithelial cells to motile mesenchymal cells. A number of microbes, including Bacteroides fragilis, Fusobacterium nucleatum, and Enterococcus faecalis have been found to produce toxins that contribute to EMT, typically through altering the normal adhesion between cells [90].

\section{Microbes Produce Quorum Sensing Molecules That Can Contribute to Metastasis}

Some microbes, including Bacillus sp., E. faecium and Escherichia coli, produce peptides that act as quorum sensing molecules (molecules that microbes use to coordinate their gene expression and behavior) that can contribute to metastasis. These quorum sensing molecules appear to alter host epithelial growth factors, which activate intracellular signaling that eventually leads to metastasis $[91 \bullet \bullet]$.

\section{Microbes Alter Cancer Cell Epigenetics to Enhance Cancer Cell Proliferation}

Microbes are capable of producing metabolites that regulate DNA expression. For example, Bifidobacterium spp. produce folate, a major methyl donor in the pathway that leads to S-adenosylmethionine, the metabolite that donates methyls to silence genes. $F$. nucleatum, frequently enriched in patients with colorectal cancer, has been correlated with DNA methylation of genes within the inflamed colonic mucosa which enhance tumorigenesis [92, 93]. Chromatin remodeling via acetylation and deacetylation of histones is also an important aspect of DNA expression regulation. The gut microbiome is thought to play a role in histone acetylation given that butyrate, a metabolite of gut microbes including Megasphaera, Roseburia, Faecalibacterium, Clostridium, etc. [94], is a potent inducer of intestinal Treg cell differentiation via histone acetylation [95]. Non-coding RNAs (microRNA, small interfering RNA, and long non-coding RNA) have also been linked to the gut microbiota and host health. Differential expression of long non-coding RNAs has been observed in cells colonized with E. coli [96]. Post-transcriptional modifications via altered microRNA expression have been noted after infection with Salmonella spp. [97] and F. nucleatum [98・•], of which $F$. nucleatum is thought to influence colon cancer via autophagy regulation. 


\section{Opportunities and Challenges in Treating Cancer Given Interactions with the Microbiome}

\section{Can We Jump Start the Immune System to Break up Microbe-Cancer Cell Cooperation?}

When the immune system is functioning properly, it limits the growth and proliferation of harmful microbes and cancer cells. Microbes and cancer cells may cooperate to create an ecological niche that allows them to proliferate outside of normal immune control. So immune therapies targeted at disrupting microbecancer cell interactions may have potential for treatment.

\section{Can Specific Microbes Be Used to Control Cancer Cell Populations as a Part of Treatment?}

Microorganisms, such as Mycobacterium bovis BCG, have been used in cancer treatments for more than 100 years, including the successful treatment of bladder cancer [40]. Additionally, many microbial products have been used in cancer treatment, including redox proteins like azurin [40]. The mechanisms of action appear to be diverse, with some activating the immune system, others inducing cell death via apoptosis and others inhibiting the growth of new blood vessels [40], thereby depriving tumors of resources. Future work should investigate the metabolic and ecological interactions between tumor cells and microbes that underlie this effect in order to discover new microbes that can be used in cancer treatments.

\section{Can Commensal Microbes Enhance the Effectiveness of Therapy?}

In mice, having intact commensal microbes leads to greater effectiveness of cancer therapy [99], but other microbes reduce the effectiveness of cancer therapy and increase resistance $[98 \bullet \bullet$. The mechanisms underlying these positive and negative effects on therapy are currently unknown. Future work exploring these interactions could have therapeutic potential.

\section{Can Foods Containing Prebiotics and Probiotics Help Prevent and Treat Cancer?}

While a few cases of adverse events in cancer patients taking probiotics have been published [100], the potential benefits of pre- and pro-biotics observed in pre-clinical models suggest that these bioactive food components may decrease cancer risk by improving intestinal barrier function, immunomodulation, and metabolic and antiproliferative effects [101]. However, prospective longitudinal data are extremely limited in humans. This work is required before making clinical recommendations.

\section{Conclusion}

Human gut microbiota play an important role in enhancing and inhibiting cancer initiation and progression. Dietary intake is an important way of shaping this community but inter-individual variability in microbiome community structure may influence how people respond to different dietary constituents. Not much is known about how dietary inputs affect microbe-cancer cell interactions, but it appears that excess energy inputs may encourage the growth of both cancer cells and pathogenic microbes. While certain microbes can enhance cancer cell fitness by promoting proliferation and protecting cancer cells from the immune system, others may protect against cancer. Nonetheless, there are many open questions with regard to how individual differences in habitual dietary intake, microbial structure and function, and human genetics contribute. Many exciting opportunities for leveraging this new work on microbe-cancer cell interactions to improve prevention and treatment exist. Future work should focus on understanding the complex dynamic interactions between cancer cells and microbes over time both in healthy individuals and cancer patients.

\section{Compliance with Ethical Standards}

Conflict of Interest Corrie M. Whisner has received compensation from Ardent Mills LLC for service as a consultant and participation on a Scientific Advisory Board.

C. Athena Aktipis is supported by National Institutes of Health grant U54 CA217376 (to the Arizona Cancer and Evolution Center); however, this grant was not used to fund efforts in the preparation of this article.

Human and Animal Rights and Informed Consent This article does not contain any studies with human or animal subjects performed by any of the authors.

Open Access This article is distributed under the terms of the Creative Commons Attribution 4.0 International License (http:// creativecommons.org/licenses/by/4.0/), which permits unrestricted use, distribution, and reproduction in any medium, provided you give appropriate credit to the original author(s) and the source, provide a link to the Creative Commons license, and indicate if changes were made.

Publisher's Note Springer Nature remains neutral with regard to jurisdictional claims in published maps and institutional affiliations.

\section{References}

Papers of particular interest, published recently, have been highlighted as:

- Of importance

-• Of major importance

1. Siegel RL, Miller KD, Jemal A. Cancer Statistics, 2017. CA Cancer J Clin. 2017;67(1):7-30. 
2. Cancer Statistics. National Cancer Institute. https://www.cancer. gov/about-cancer/understanding/statistics. Published April 2, 2015. Accessed September 8, 2018

3. Clemente JC, Ursell LK, Parfrey LW, Knight R. The impact of the gut microbiota on human health: an integrative view. Cell. 2012;148(6):1258-70.

4. Sender R, Fuchs S, Milo R. Revised estimates for the number of human and bacteria cells in the body. PLoS Biol. 2016;14(8): e1002533.

5. Qin J, Li R, Raes J, et al. A human gut microbial gene catalogue established by metagenomic sequencing. Nature. 2010;464(7285):59-65.

6. Jandhyala SM, Talukdar R, Subramanyam C, Vuyyuru H, Sasikala M, Nageshwar Reddy D. Role of the normal gut microbiota. World J Gastroenterol. 2015;21(29):8787-803.

7. Meng C, Bai C, Brown TD, Hood LE, Tian Q. Human gut microbiota and gastrointestinal cancer. Genomics Proteomics Bioinformatics. 2018;16(1):33-49.

8. Shreiner AB, Kao JY, Young VB. The gut microbiome in health and in disease. Curr Opin Gastroenterol. 2015;31(1):69-75.

9. Ley RE, Knight R, Gordon JI. The human microbiome: eliminating the biomedical/environmental dichotomy in microbial ecology. Environ Microbiol. 2007;9(1):3-4.

10. Natividad JMM, Verdu EF. Modulation of intestinal barrier by intestinal microbiota: pathological and therapeutic implications. Pharmacol Res. 2013;69(1):42-51.

11. de Martel C, Ferlay J, Franceschi S, Vignat J, Bray F, Forman D, et al. Global burden of cancers attributable to infections in 2008: a review and synthetic analysis. Lancet Oncol. 2012;13(6):607-15.

12. Aktipis CA, Boddy AM, Jansen G, Hibner U, Hochberg ME, Maley CC, et al. Cancer across the tree of life: cooperation and cheating in multicellularity. Philos Trans R Soc Lond Ser B Biol Sci. 2015;370(1673):20140219. https://doi.org/10.1098/rstb. 2014.0219

13. Wasielewski H, Alcock J, Aktipis A. Resource conflict and cooperation between human host and gut microbiota: implications for nutrition and health. Ann N Y Acad Sci. 2016;1372(1):20-8.

14. Polyak K, Haviv I, Campbell IG. Co-evolution of tumor cells and their microenvironment. Trends Genet. 2009;25(1):30-8.

15. Merlo LF, Pepper JW, Reid BJ, Maley CC. Cancer as an evolutionary and ecological process. Nat Rev Cancer. 2006;6(12):924 35.

16. de Visser KE, Eichten A, Coussens LM. Paradoxical roles of the immune system during cancer development. Nat Rev Cancer. 2006;6(1):24-37.

17. Coussens LM, Werb Z. Inflammation and cancer. Nature. 2002;420(6917):860-7.

18. Quail DF, Joyce JA. Microenvironmental regulation of tumor progression and metastasis. Nat Med. 2013;19(11):1423-37.

19. Aktipis CA, Nesse RM. Evolutionary foundations for cancer biology. Evol Appl. 2013;6(1):144-59.

20. Buc E, Dubois D, Sauvanet P, Raisch J, Delmas J, DarfeuilleMichaud A, et al. High prevalence of mucosa-associated E. coli producing cyclomodulin and genotoxin in colon cancer. PLoS One. 2013;8(2):e56964.

21. Dalmasso G, Cougnoux A, Delmas J, Darfeuille-Michaud A, Bonnet R. The bacterial genotoxin colibactin promotes colon tumor growth by modifying the tumor microenvironment. Gut Microbes. 2014;5(5):675-80.

22. Dejea CM, Wick EC, Hechenbleikner EM, White JR, Mark Welch $\mathrm{JL}$, Rossetti BJ, et al. Microbiota organization is a distinct feature of proximal colorectal cancers. Proc Natl Acad Sci U S A. 2014;111(51):18321-6.

23. David LA, Maurice CF, Carmody RN, Gootenberg DB, Button JE, Wolfe BE, et al. Diet rapidly and reproducibly alters the human gut microbiome. Nature. 2014;505(7484):559-63.
24. Muegge BD, Kuczynski J, Knights D, Clemente JC, Gonzalez A, Fontana L, et al. Diet drives convergence in gut microbiome functions across mammalian phylogeny and within humans. Science. 2011;332(6032):970-4.

25. Wu GD, Chen J, Hoffmann C, Bittinger K, Chen YY, Keilbaugh SA, et al. Linking long-term dietary patterns with gut microbial enterotypes. Science. 2011;334(6052):105-8.

26. De Filippo C, Cavalieri D, Di Paola M, et al. Impact of diet in shaping gut microbiota revealed by a comparative study in children from Europe and rural Africa. Proc Natl Acad Sci U S A. 2010;107(33):14691-6.

27. Newmark HL, Yang K, Kurihara N, Fan K, Augenlicht LH, Lipkin M. Western-style diet-induced colonic tumors and their modulation by calcium and vitamin $\mathrm{D}$ in $\mathrm{C} 57 \mathrm{~B} 1 / 6$ mice: a preclinical model for human sporadic colon cancer. Carcinogenesis. 2009;30(1):88-92.

28. Newmark HL, Yang K, Lipkin M, Kopelovich L, Liu Y, Fan K, et al. A Western-style diet induces benign and malignant neoplasms in the colon of normal C57B1/6 mice. Carcinogenesis. 2001;22(11):1871-5.

29. Longo VD, Fontana L. Calorie restriction and cancer prevention: metabolic and molecular mechanisms. Trends Pharmacol Sci. 2010;31(2):89-98.

30. Turnbaugh PJ, Ley RE, Mahowald MA, Magrini V, Mardis ER, Gordon JI. An obesity-associated gut microbiome with increased capacity for energy harvest. Nature. 2006;444(7122):1027-31.

31. Ridaura VK, Faith JJ, Rey FE, Cheng J, Duncan AE, Kau AL, et al. Gut microbiota from twins discordant for obesity modulate metabolism in mice. Science. 2013;341(6150):1241214.

32. Schwiertz A, Taras D, Schäfer K, Beijer S, Bos NA, Donus C, et al. Microbiota and SCFA in lean and overweight healthy subjects. Obesity. 2010;18(1):190-5.

33. Cani PD, Jordan BF. Gut microbiota-mediated inflammation in obesity: a link with gastrointestinal cancer. Nat Rev Gastroenterol Hepatol. 2018;15:671-82. https://doi.org/10.1038/ s41575-018-0025-6.

34. Ott B, Skurk T, Hastreiter L, et al. Effect of caloric restriction on gut permeability, inflammation markers, and fecal microbiota in obese women. Sci Rep. 2017;7(1):11955 This paper expands knowledge of caloric restriction diets on gut microbial communities, gut barrier function, and weight loss in a cohort of obese women. Findings from this work may inform cancer research as similar inflammatory and gut barrier mechanisms have been implicated in cancer research. Interestingly, the authors did not find major consistent changes in microbial abundance in the intestines of women following very lowcalorie diets; however, reductions in inflammatory markers CRP and lipopolysaccharide were observed.

35. Fraumene C, Manghina V, Cadoni E, et al. Caloric restriction promotes rapid expansion and long-lasting increase of Lactobacillus in the rat fecal microbiota. Gut Microbes. 2018;9(2):104-14 This paper suggests that caloric restriction in rats, at a young age, may allow beneficial alterations to the gut microbiome to persist into adulthood. Specifically, caloric restriction significantly increased the abundance of potentially beneficial Lactobacillus.

36. Tollefsbol TO. Dietary epigenetics in cancer and aging. Cancer Treat Res. 2014;159:257-67.

37. O'Flanagan CH, Smith LA, McDonell SB, Hursting SD. When less may be more: calorie restriction and response to cancer therapy. BMC Med. 2017;15(1):106.

38. Vander Heiden MG, Cantley LC, Thompson CB. Understanding the Warburg effect: the metabolic requirements of cell proliferation. Science. 2009;324(5930):1029-33. 
39. Duncan SH, Louis P, Flint HJ. Lactate-utilizing bacteria, isolated from human feces, that produce butyrate as a major fermentation product. Appl Environ Microbiol. 2004;70(10):5810-7.

40. Chakrabarty AM. Microorganisms and cancer: quest for a therapy. J Bacteriol. 2003;185(9):2683-6.

41. Hochberg Z. An evolutionary perspective on the obesity epidemic. Trends Endocrinol Metab. 2018;29:819-26. https://doi.org/10. 1016/j.tem.2018.09.002.

42. La Vecchia C, Franceschi S, Dolara P, Bidoli E, Barbone F. Refined-sugar intake and the risk of colorectal cancer in humans. Int J Cancer. 1993;55(3):386-9.

43. Makarem N, Lin Y, Bandera EV, Jacques PF, Parekh N. Concordance with World Cancer Research Fund/American Institute for Cancer Research (WCRF/AICR) guidelines for cancer prevention and obesity-related cancer risk in the Framingham Offspring cohort (1991-2008). Cancer Causes Control. 2015;26(2):277-86.

44. Gill SR, Pop M, Deboy RT, et al. Metagenomic analysis of the human distal gut microbiome. Science. 2006;312(5778):1355-9.

45. Ríos-Covián D, Ruas-Madiedo P, Margolles A, Gueimonde M, de Los Reyes-Gavilán CG, Salazar N. Intestinal short chain fatty acids and their link with diet and human health. Front Microbiol. 2016;7:185.

46. Augeron C, Laboisse CL. Emergence of permanently differentiated cell clones in a human colonic cancer cell line in culture after treatment with sodium butyrate. Cancer Res. 1984;44(9):3961-9.

47. Hague A, Manning AM, Hanlon KA, Huschtscha LI, Hart D, Paraskeva C. Sodium butyrate induces apoptosis in human colonic tumour cell lines in a p53-independent pathway: implications for the possible role of dietary fibre in the prevention of large-bowel cancer. Int J Cancer. 1993;55(3):498-505.

48. Donohoe DR, Holley D, Collins LB, Montgomery SA, Whitmore AC, Hillhouse A, et al. A gnotobiotic mouse model demonstrates that dietary fiber protects against colorectal tumorigenesis in a microbiota- and butyrate-dependent manner. Cancer Discov. 2014;4(12):1387-97.

49. Belcheva A, Irrazabal T, Robertson SJ, Streutker C, Maughan H, Rubino S, et al. Gut microbial metabolism drives transformation of MSH2-deficient colon epithelial cells. Cell. 2014;158(2):28899.

50. Perry RJ, Peng L, Barry NA, Cline GW, Zhang D, Cardone RL, et al. Acetate mediates a microbiome-brain- $\beta$-cell axis to promote metabolic syndrome. Nature. 2016;534(7606):213-7.

51. Murphy EF, Cotter PD, Healy S, Marques TM, O'Sullivan O, Fouhy $\mathrm{F}$, et al. Composition and energy harvesting capacity of the gut microbiota: relationship to diet, obesity and time in mouse models. Gut. 2010;59(12):1635-42.

52. Romagnolo DF, Selmin OI. Flavonoids and cancer prevention: a review of the evidence. J Nutr Gerontol Geriatr. 2012;31(3):20638.

53. Chang H, Lei L, Zhou Y, Ye F, Zhao G. Dietary flavonoids and the risk of colorectal cancer: an updated meta-analysis of epidemiological studies. Nutrients 2018;10(7):950. https://doi.org/10.3390/ nu10070950.

54. Watson GW, Beaver LM, Williams DE, Dashwood RH, Ho E. Phytochemicals from cruciferous vegetables, epigenetics, and prostate cancer prevention. AAPS J. 2013;15(4):951-61.

55. Abdull Razis AF, Noor NM. Cruciferous vegetables: dietary phytochemicals for cancer prevention. Asian Pac J Cancer Prev. 2013;14(3):1565-70.

56. Li F, Hullar MAJ, Schwarz Y, Lampe JW. Human gut bacterial communities are altered by addition of cruciferous vegetables to a controlled fruit- and vegetable-free diet. J Nutr. 2009;139(9): 1685-91.

57. Salonen A, Lahti L, Salojärvi J, Holtrop G, Korpela K, Duncan $\mathrm{SH}$, et al. Impact of diet and individual variation on intestinal microbiota composition and fermentation products in obese men. ISME J. 2014;8(11):2218-30.

58. Desai MS, Seekatz AM, Koropatkin NM, et al. A dietary fiberdeprived gut microbiota degrades the colonic mucus barrier and enhances pathogen susceptibility. Cell. 2016;167(5):13391353.e21 This paper supports the importance of dietary fiber in maintaining the intestinal mucus barrier, as low-fiber diets promoted the abundance of mucus-degrading microbes. In the absence of dietary fiber, gut microbes were driven to rely on mucus glycoproteins rather than non-digested complex carbohydrates which reduced intestinal barrier function, thereby increasing inflammation and susceptibility to pathogens. Most interesting was the finding that prebiotic supplementation, while correcting the microbiome transcriptome, was unable to correct the erosion of intestinal mucus.

59. Ziaei S, Halaby R. Dietary isoflavones and breast cancer risk. Medicines (Basel) 2017;4(2):18. https://doi.org/10.3390/ medicines4020018.

60. Rowland IR, Wiseman H, Sanders TA, Adlercreutz H, Bowey EA. Interindividual variation in metabolism of soy isoflavones and lignans: influence of habitual diet on equol production by the gut microflora. Nutr Cancer. 2000;36(1):27-32.

61. Nyangale EP, Mottram DS, Gibson GR. Gut microbial activity, implications for health and disease: the potential role of metabolite analysis. J Proteome Res. 2012;11(12):5573-85.

62. Joyce SA, Gahan CGM. Disease-associated changes in bile acid profiles and links to altered gut microbiota. Dig Dis. 2017;35(3): 169-77.

63. Bernstein C, Holubec H, Bhattacharyya AK, Nguyen H, Payne $\mathrm{CM}$, Zaitlin B, et al. Carcinogenicity of deoxycholate, a secondary bile acid. Arch Toxicol. 2011;85(8):863-71.

64. Bernstein C, Payne CM, Bernstein H. Bile acids: promoters or carcinogens in colon cancer. J Carcinogene Mutagene. 2011;2: $101 \mathrm{e}$.

65. Russell WR, Gratz SW, Duncan SH, Holtrop G, Ince J, Scobbie L, et al. High-protein, reduced-carbohydrate weight-loss diets promote metabolite profiles likely to be detrimental to colonic health. Am J Clin Nutr. 2011;93(5):1062-72.

66. O'Keefe SJD, Li JV, Lahti L, Ou J, Carbonero F, Mohammed K, et al. Fat, fibre and cancer risk in African Americans and rural Africans. Nat Commun. 2015;6:6342.

67. O'Keefe SJ, Kidd M, Espitalier-Noel G, Owira P. Rarity of colon cancer in Africans is associated with low animal product consumption, not fiber. Am J Gastroenterol. 1999;94(5):1373-80.

68. Fletcher JA, Doebeli M. A simple and general explanation for the evolution of altruism. Proc R Soc B Biol Sci. 2009;276(1654):13-9.

69. Noe R, Hammerstein P. Biological markets: supply and demand determine the effect of partner choice in cooperation, mutualism and mating. Behav Ecol Sociobiol. 1994;35(1):1-11 \%@ 03405443.

70. Aktipis CA. Know when to walk away: contingent movement and the evolution of cooperation. J Theor Biol. 2004;231(2):249-60.

71. Aktipis A, Cronk L, Alcock J, et al. Understanding cooperation through fitness interdependence. Nat Hum Behav. 2018;2:429431.

72. Nougayrède J-P, Homburg S, Taieb F, Boury M, Brzuszkiewicz E, Gottschalk G, et al. Escherichia coli induces DNA double-strand breaks in eukaryotic cells. Science. 2006;313(5788):848-51.

73. Bhatt AP, Redinbo MR, Bultman SJ. The role of the microbiome in cancer development and therapy. CA Cancer J Clin. 2017;67(4): 326-44.

74. Goodwin AC, Destefano Shields CE, Wu S, et al. Polyamine catabolism contributes to enterotoxigenic Bacteroides fragilisinduced colon tumorigenesis. Proc Natl Acad Sci U S A. 2011;108(37):15354-9. 
75. Watanabe T, Tada M, Nagai H, Sasaki S, Nakao M. Helicobacter pylori infection induces gastric cancer in mongolian gerbils. Gastroenterology. 1998;115(3):642-8.

76. Helicobacter and Cancer Collaborative Group. Gastric cancer and Helicobacter pylori: a combined analysis of 12 case control studies nested within prospective cohorts. Gut. 2001;49(3):347-53.

77. Chang AH, Parsonnet J. Role of bacteria in oncogenesis. Clin Microbiol Rev. 2010;23(4):837-57.

78.• Suarez G, Romero-Gallo J, Sierra JC, et al. Genetic manipulation of helicobacter pylori virulence function by host carcinogenic phenotypes. Cancer Res. 2017;77(9):2401-12 This in vivo work in a rodent model of human gastric cancer highlights that $H$. pylori pathogenesis and influence on gastric cancer is related to host phenotype. This work further suggests the integrated role of gut microbes in cancer progression via host-integration of microbial virulence factors.

79. Amieva M, Peek RM Jr. Pathobiology of Helicobacter pyloriinduced gastric cancer. Gastroenterology. 2016;150(1):64-78.

80. Cougnoux A, Dalmasso G, Martinez R, Buc E, Delmas J, Gibold $\mathrm{L}$, et al. Bacterial genotoxin colibactin promotes colon tumour growth by inducing a senescence-associated secretory phenotype. Gut. 2014;63(12):1932-42.

81. Hussell T, Isaacson PG, Crabtree JE, Spencer J. Helicobacter pylori-specific tumour-infiltrating $\mathrm{T}$ cells provide contact dependent help for the growth of malignant B cells in low-grade gastric lymphoma of mucosa-associated lymphoid tissue. J Pathol. 1996;178(2):122-7.

82. Lecuit M, Abachin E, Martin A, Poyart C, Pochart P, Suarez F, et al. Immunoproliferative small intestinal disease associated with Campylobacter jejuni. N Engl J Med. 2004;350(3):239-48.

83. Ferreri AJM, Govi S, Pasini E, Mappa S, Bertoni F, Zaja F, et al. Chlamydophila psittaci eradication with doxycycline as first-line targeted therapy for ocular adnexae lymphoma: final results of an international phase II trial. J Clin Oncol. 2012;30(24):2988-94.

84. Wu S, Rhee K-J, Albesiano E, Rabizadeh S, Wu X, Yen HR, et al. A human colonic commensal promotes colon tumorigenesis via activation of $\mathrm{T}$ helper type $17 \mathrm{~T}$ cell responses. Nat Med. 2009;15(9):1016-22.

85. Goodman B, Gardner H. The microbiome and cancer. J Pathol. 2018;244(5):667-76.

86. Garrett WS. Cancer and the microbiota. Science. 2015;348(6230): $80-6$.

87. Flemming H-C, Wingender J. The biofilm matrix. Nat Rev Microbiol. 2010;8(9):623-33.

88. Williams VM, Filippova M, Soto U, Duerksen-Hughes PJ. HPVDNA integration and carcinogenesis: putative roles for inflammation and oxidative stress. Future Virol. 2011;6(1):45-57.

89. Rubinstein MR, Wang X, Liu W, Hao Y, Cai G, Han YW. Fusobacterium nucleatum promotes colorectal carcinogenesis by modulating E-cadherin/ $\beta$-catenin signaling via its FadA adhesin. Cell Host Microbe. 2013;14(2):195-206.

90. Gaines S, Williamson AJ, Hyman N, Kandel J. How the microbiome is shaping our understanding of cancer biology and its treatment. Semin Colon Rectal Surg. 2018;29(1):12-6.
91.• Wynendaele E, Verbeke F, D'Hondt M, et al. Crosstalk between the microbiome and cancer cells by quorum sensing peptides. Peptides. 2015;64:40-8 This paper is one of the first to expand current knowledge on how gut microbes interact with human cells to influence health and disease. The authors report on several quorum sensing peptides produced by specific microbial species that initiate cancer cell invasion in the colon and further promote angiogenisis and metastasis of cancer tissue.

92. Tahara T, Hirata I, Nakano N, Tahara S, Horiguchi N, Kawamura T, et al. Potential link between Fusobacterium enrichment and DNA methylation accumulation in the inflammatory colonic mucosa in ulcerative colitis. Oncotarget. 2017;8(37):61917-26.

93. Ito M, Kanno S, Nosho K, Sukawa Y, Mitsuhashi K, Kurihara H, et al. Association of Fusobacterium nucleatum with clinical and molecular features in colorectal serrated pathway. Int J Cancer. 2015;137(6):1258-68.

94. Demehri FR, Frykman PK, Cheng Z, Ruan C, Wester T, Nordenskjöld A, et al. Altered fecal short chain fatty acid composition in children with a history of Hirschsprung-associated enterocolitis. J Pediatr Surg. 2016;51(1):81-6.

95. Furusawa Y, Obata Y, Fukuda S, Endo TA, Nakato G, Takahashi $\mathrm{D}$, et al. Commensal microbe-derived butyrate induces the differentiation of colonic regulatory T cells. Nature. 2013;504(7480): 446-50.

96. Liang L, Ai L, Qian J, Fang J-Y, Xu J. Long noncoding RNA expression profiles in gut tissues constitute molecular signatures that reflect the types of microbes. Sci Rep. 2015;5:11763.

97. Maudet C, Mano M, Sunkavalli U, Sharan M, Giacca M, Förstner $\mathrm{KU}$, et al. Functional high-throughput screening identifies the miR-15 microRNA family as cellular restriction factors for Salmonella infection. Nat Commun. 2014;5:4718.

98.• Yu T, Guo F, Yu Y, et al. Fusobacterium nucleatum promotes chemoresistance to colorectal cancer by modulating autophagy. Cell. 2017;170(3):548-563.e16 This reference provides clinical, mechanistic, and functional data to support the ability of pathogen Fusobacterium nucleatum to mediate resistance to chemotherapy in recurrent colon cancer patients. $F$. nucleatum appears to facilitate this response by interacting with human cell gene expression at the tumor site, specifically through integrated Toll-like receptor, microRNA, and autophagy signaling which ultimately inhibit apoptosis.

99. Iida N, Dzutsev A, Stewart CA, Smith L, Bouladoux N, Weingarten RA, et al. Commensal bacteria control cancer response to therapy by modulating the tumor microenvironment. Science. 2013;342(6161):967-70.

100. Cesaro S, Chinello P, Rossi L, Zanesco L. Saccharomyces cerevisiae fungemia in a neutropenic patient treated with Saccharomyces boulardii. Support Care Cancer. 2000;8(6):504-5.

101. Scott AJ, Merrifield CA, Younes JA, Pekelharing EP. Pre-, proand synbiotics in cancer prevention and treatment - a review of basic and clinical research. Ecancermedicalscience. 2018;12:869. 